\title{
Use of polypropylene fiber and silica fume modified concrete as a repair material
}

\author{
Jing Liu ${ }^{*}$, Wen $\mathrm{Liu}^{2}$, Shugang Guan², Chao $\mathrm{Guo}^{2}$, and Xinguo Zheng ${ }^{1}$ \\ ${ }^{1}$ Railway Engineering Research Institute of China Academy of Railway Sciences, Daliushu Road No.2, 100081, Beijing, China \\ ${ }^{2}$ Shanghai Railway Bureau, Tianmu East Road, 200071, Shanghai, China
}

\begin{abstract}
Polypropylene fiber and silica fume were used to get high impermeability and cracking resistance concrete as a repair material. Results showed just incorporating fiber (without silica fume) had no obvious improvement on strength and impermeability of concrete. The usage of polypropylene fiber and silica fume together in concrete increased the compressive strength and caused a significant reduction in chloride permeability. The improvement of fiber and silica fume on concrete properties was attributed to both the anti-cracking effect from polypropylene fiber and densification reinforcement action to the interfacial transition zones of both fiber-matrix and aggregate - cement paste from silica fume. These properties made them suitable for certain applications such as concrete repairs.
\end{abstract}

\section{Introduction}

In China, a lot of major infrastructures are being built and will be built in the marine and coastal environment, such as coastal railway, sea-crossing bridges and tunnels, ports and harbors, oil drilling platforms, parking apron, etc. These buildings were generally built with concrete which was the most widely-used construction materials because of low cost, high compressive strength, high durability and versatility. Since these major infrastructures played an important role in the national economy, high durability of concrete was required necessarily, and the service life requirement was generally more than 100 years. But the survey of buildings durability in the marine environment at home and abroad indicated many concrete structures appeared premature destruction and deterioration in just 20 to 30 years after being built, far from reaching the designed service life and had to be rehabilitated. Repair and strengthening in order to improve the durability of these structures became critical [1-3].

As we know, concrete is intrinsically porous and may deteriorate or depredate as a result of harsh environmental exposure such as marine environment. The deterioration effect on concrete structure had led to the realization that durability of concrete should be improved by adding into extra suitable constituent materials in normal concrete. An effective way to minimize durability problem is to make the composite less permeable and the paste denser or to inhibit crack propagation and provide enough cover thickness for concrete structures especially in the marine environment [4-5].
Therefore, use of polypropylene fiber and silica fume modified concrete as a repair material to improve the durability of these structures was studied by experiments including compressive strength, rapid chloride penetration and accelerated corrosion potential test of steel bar in concrete. The aim of the study was to research and develop a kind of concrete with high compactness and cracking resistance properties, and then to provide more durable materials as a repair material.

\section{Experimental Methodology}

\subsection{Materials}

(1) Cement: 42.5 normal hardening Portland cement (C) confirming to GB 175 was used; its compressive strength at $28 \mathrm{~d}$ was $46.3 \mathrm{MPa}$.

(2) Fine aggregate: Locally available natural sand with a specific gravity of 2.69 and fineness modulus of 2.7 was used.

(3) Coarse aggregate: Locally available crushed stone with a maximum nominal size of $19 \mathrm{~mm}$ and crushed index of 7.8 was used.

(4) Mineral admixtures: Level I fly ash production (FA) with specific surface area of $5400 \mathrm{~cm}^{2} / \mathrm{g}$ was used; Silica fume with specific surface area of $35000 \mathrm{~m}^{2} / \mathrm{kg}$ was used.

(5) Superplasticizer: Polycarboxylate superplasticizer confirming to GB 8076 with $30 \%$ water reducing rate was used.

(6) Fiber : Polypropylene monofilament fiber with density of $0.91 \mathrm{~g} / \mathrm{cm}^{3}$, length of $19 \mathrm{~mm}$, diameter of 18 48 $\mu \mathrm{m}$ was used.

\footnotetext{
* Corresponding author: 705478890@qq.com
} 
The chemical compositions of cement, fly ash and silica fume are given in Table 1.

Table 1. Chemical composition of cement, fly ash and silica fume $/ \%$

\begin{tabular}{c|c|c|c|c|c|c}
\hline & $\mathrm{SiO}_{2}$ & $\mathrm{Al}_{2} \mathrm{O}_{3}$ & $\mathrm{Fe}_{2} \mathrm{O}_{3}$ & $\mathrm{CaO}$ & $\mathrm{MgO}$ & $\mathrm{SO}_{3}$ \\
\hline $\begin{array}{c}\text { P.O } \\
42.5\end{array}$ & 24.3 & 4.9 & 3.8 & 55.2 & 4.3 & 2.2 \\
\hline $\mathrm{FA}$ & 52.8 & 25.7 & 9.7 & 3.7 & 1.2 & 0.2 \\
\hline $\mathrm{SF}$ & 85.36 & 0.06 & 7.04 & 0.56 & 1.10 & - \\
\hline
\end{tabular}

\subsection{Concrete mix proportions}

Mixture proportions of HPC were given in Table 2. The water/binder ratio and sand/coarse aggregate ratio for every mix was 0.32 and $40 \%$, respectively.

Table 2. Mixture proportions of concrete and slump

\begin{tabular}{c|c|c|c}
\hline Mix No. & $\mathrm{C} 0$ & $\mathrm{C} 1$ & $\mathrm{C} 2$ \\
\hline $\mathrm{C}\left(\mathrm{kg} / \mathrm{m}^{3}\right)$ & 360 & 360 & 360 \\
\hline $\mathrm{FA}\left(\mathrm{kg} / \mathrm{m}^{3}\right)$ & 120 & 120 & 96 \\
\hline $\mathrm{SF}\left(\mathrm{kg} / \mathrm{m}^{3}\right)$ & 0 & 0 & 24 \\
\hline Fiber $\left(\mathrm{kg} / \mathrm{m}^{3}\right)$ & 0 & 0.9 & 0.9 \\
\hline Superplasticizer\# & $0.40 \%$ & $0.60 \%$ & $0.60 \%$ \\
\hline Slump $(\mathrm{cm})$ & 21.5 & 21 & 19.5 \\
\hline
\end{tabular}

\# represents dosage of superplasticizer is the percentage of binder in weight.

\section{Experimental methods}

\subsection{Compressive strength test}

In accordance with "Standard for test method of mechanical properties on ordinary concrete" (GB/T50081-2002), the cubic specimen size is $150 \times 150$ $\times 150 \mathrm{~mm}$.

\subsection{Chloride permeability test}

PVC pipes were used to make cylinder specimens with the dimension of $16 \mathrm{~cm}$ (diameter) $\times 100 \mathrm{~cm}$ (height). After consolidated, specimens were cured in the standard condition. Three groups of $\Phi 100 \mathrm{~mm} \times 50 \mathrm{~mm}$ cylinders were cut and cored in the upper, middle and lower of the specimens, respectively. Every group had three specimens. Specific coring positions: in the upper coring downwards $50 \mathrm{~mm}$ from the top; in the middle coring the center of specimen; in the lower coring upwards $50 \mathrm{~mm}$ from the bottom. The Nordtest NT build 492 method was used to test chloride diffusion coefficient of specimens coring from different height positions. The concrete age was 28 days when testing.

\subsection{Corrosion potential of steel bar}

One end of $\Phi 20 \mathrm{~mm} \times 250 \mathrm{~mm}$ steel bar was located in the central concrete cylinder with the dimension of $\Phi 150$ $\mathrm{mm} \times 250 \mathrm{~mm}$. Specimens were cured in the standard condition $\left(20 \pm 2^{\circ} \mathrm{C},>90 \% \mathrm{RH}\right)$ for 28 days before test. A sketch of corrosion potential measurement equipment was shown in Fig.1. The steel bar was sealed with epoxy coating except the area where corrosion was monitored. Both ends of concrete cylinder were also sealed with impermeable coating to insure the ingress of chloride only from surrounding perimeter. To accelerate the corrosion of reinforcement, $30 \mathrm{~V}$ direct voltage was imposed. The potential difference between steel bar and the reference electrode was measured every 24 hours in the absence of applied voltage, which was called the corrosion potential (Ecorr). Based on ASTM C876-91 steel corrosion potential evaluation criteria, when corrosion potential was less than $-426 \mathrm{mV}$, it means the corrosion of steel was very severe. The time for the corrosion potential reaching $-426 \mathrm{mV}$ and declining rate were used to evaluate the concrete protective performance of steel bar.

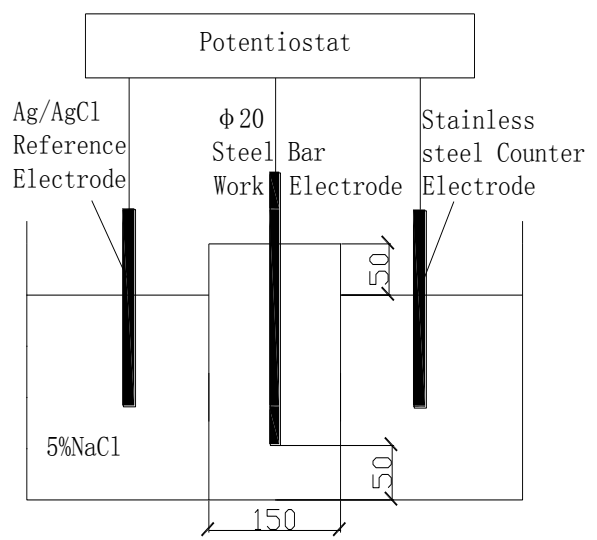

Fig. 1. A sketch of corrosion potential measurement

\section{Results and discussion}

\subsection{Compressive strength}

As shown in Fig.2, the compressive strength of $\mathrm{C} 1$ was slightly lower than that of $\mathrm{C} 0$ all the time; the compressive strength of $\mathrm{C} 2$ was significantly higher than that of $\mathrm{C} 0$ and $\mathrm{C} 1$, especially higher nearly $10 \mathrm{MPa}$ at the age of 28 days. These may be due to on one hand polypropylene fiber were soft and thin, and the surface was hydrophobic. This might cause a great deal of weak interfacial transition zone was formed between fiber and matrix when cement hardened, so the water/cement ratio there was higher resulting in more porous and internal weak interfaces. It had adverse effects on mechanical strength of concrete; on the other hand super fine silica fume could effectively fill the pore gaps between gel and fiber to make the matrix and interfacial transition zone denser. The hydration of silica fume improved and 
enhanced weak interfaces, not only eliminated adverse effects of fiber on strength also increased compressive strength [6].

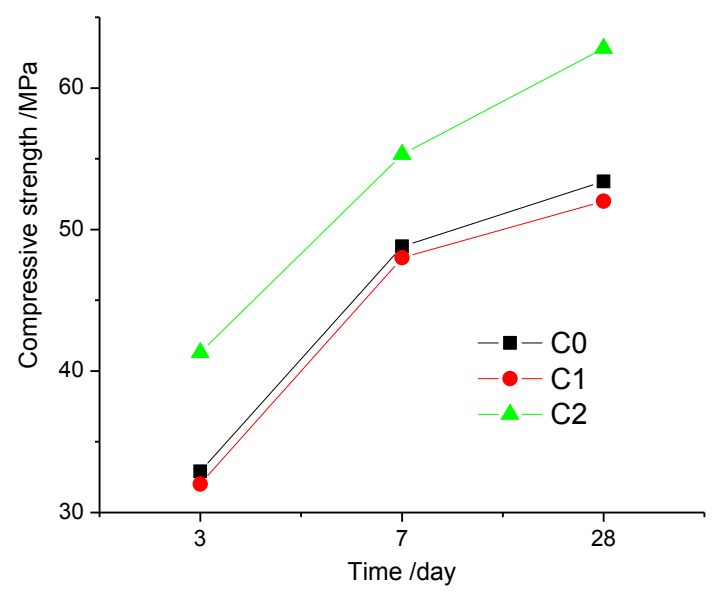

Fig. 2. Compressive strength of different mix concrete

\subsection{Chloride permeability performance}

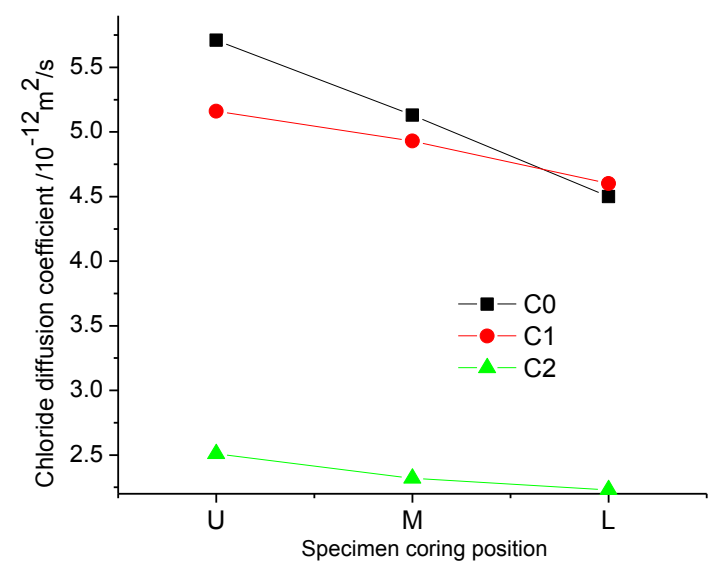

Fig. 3.Chloride diffusion coefficient at different position

U, M, L----represents the Upper, Middle, Lower position of the specimen explained in the test procedure 3.2.1, respectively.

As shown in Fig.3, the chloride diffusion coefficient of $\mathrm{C} 2$ was significantly lower than that of $\mathrm{C} 0$ and $\mathrm{C} 1$ in the upper, middle and lower position. On one hand it was due to the filling effect of silica fume, on the other hand silica fume and $\mathrm{Ca}(\mathrm{OH})_{2}$ occurred the secondary hydration to generate $\mathrm{C}-\mathrm{S}-\mathrm{H}$ gel, then the pore structures of hydrated cement paste had been changed by reducing the diameter greater than $0.5 \mu \mathrm{m}$ pores and increasing the diameter less than $0.02 \mu \mathrm{m}$ pores. Pores were refined. The reaction of silica fume made capillary porous more tortuous to extend or blocked the permeable channel; while the amount and size of $\mathrm{Ca}(\mathrm{OH})_{2}$ crystals were reduced and its directional enrichment was also alleviated, which reduced concrete porosity efficiently.

With coring positions changing from upper to lower (U-M-L), the chloride diffusion coefficient showed a downward trend, of which $\mathrm{C} 0$ was the most obvious, its chloride diffusion coefficient in the upper was higher than the middle and lower parts by $12 \%$ and $23 \%$, respectively. However, the chloride diffusion coefficient fluctuations of $\mathrm{C} 1$ and $\mathrm{C} 2$ were much gentler. For $\mathrm{C} 2$, the difference between upper and lower was only $8 \%$. It showed that when the concrete-pouring at a higher altitude, consolidation especially over vibration made water or paste easy to float up and bleed, which caused the upper water-binder ratio was higher than the lower in the same concrete placement layer; While the specific gravity of aggregate was greater, the sedimentation of aggregates could cause many tiny settlement cracks before hardening. So the lower concrete impermeability was higher than the upper's. When adding some fiber, the overall uniformity and consistency of fresh concrete were enhanced, and the trend to bleeding and segregating was reduced just like the matrix formed into $3 \mathrm{D}$ grids by fiber. Equal dispersion in the matrix of fiber alleviated coarse aggregates subsiding and water floating, which hindered the amount and scale of settlement cracks. Moreover, silica fume could further reduce bleeding because of its very small particles and huge specific surface area. Thus for the discrete of chloride permeability at different placement heights, C2 was the smallest followed by $\mathrm{C} 1$ and $\mathrm{C} 0$. So the addition of fiber and silica fume could ensure the uniformity and stability of hardened concrete best.

\subsection{Corrosion potential of steel bar}

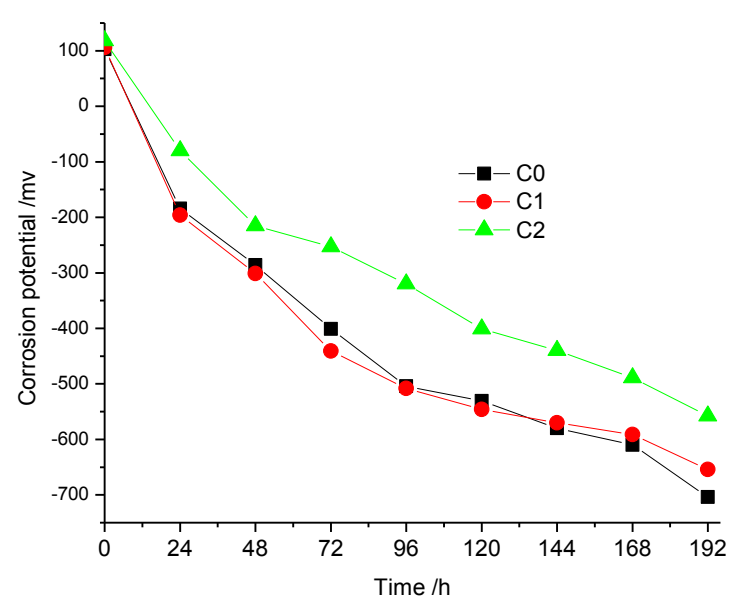

Fig. 4. Corrosion potential alteration of steel bar in concrete

The sequence for steel corrosion potential reaching -426 mv indicating serious corrosion of steel bar in concrete was $\mathrm{C} 1, \mathrm{C} 0$ and $\mathrm{C} 2$ shown in Fig.4. And the corrosion potential of $\mathrm{C} 2$ was higher than that of $\mathrm{C} 0$ and $\mathrm{C} 1$ in the same period; the cylinders of $\mathrm{C} 0$ and $\mathrm{C} 1$ could be seen emerging cracks in the 96 hours after electrification, while cylinders of $\mathrm{C} 2$ had no cracks at that time. This indicated $\mathrm{C} 2$ had better steel bar protecting performance. Chloride ions could penetrate through the concrete cover and migrate to steel surface rapidly in the electric field. When the concentration reached a critical value, chloride could cause the passive films of steel bar begin to corrode into $\mathrm{Fe}^{2+}$. 


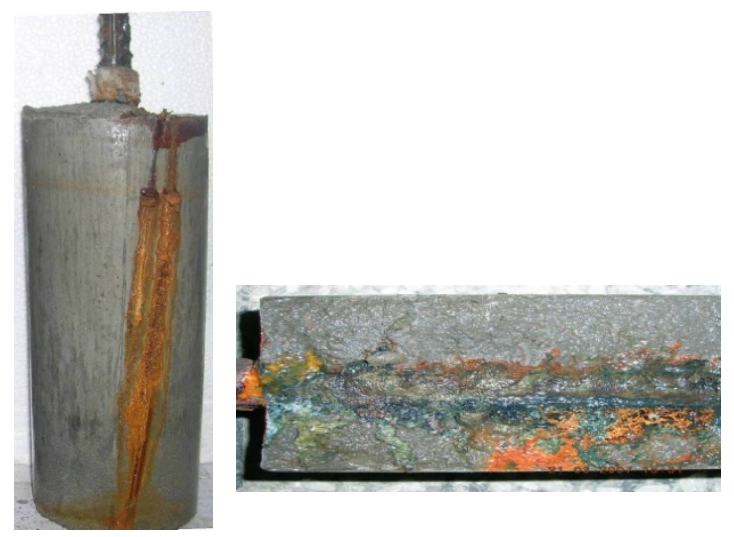

Fig. 5. Cover cracking of $\mathrm{C} 0$ and corrosion situation of steel bar in $\mathrm{C} 0$.

With the sustaining enrichment of chloride, $\mathrm{Fe}^{2+}$ and $\mathrm{Cl}^{-}$ generate water-soluble $\mathrm{FeCl}_{2}$, and then diffused outward and formed into $\mathrm{Fe}(\mathrm{OH})_{2}$ with $\mathrm{OH}$ - in the pore solution; latterly it transfered into other rust when meeting oxygen. The volume of rusted productions expanded 2-7 times which generated great tensile pressure and caused cover cracking (Fig.5). Chloride ions released and newly penetrated could migrate to the anode again and brought out more $\mathrm{Fe}^{2+}$. The corrosion of steel became more and more serious causing steel corrosion potential of the steel bar getting smaller and smaller. $\mathrm{Cl}^{-}$were not consumed and only to catalyze the corrosion. Based on the electrochemical mechanism, the above results indicated the HPC with fiber and silica fume not only possessed a relatively higher external electrical impedance to reduce the volume of external $\mathrm{Cl}^{-}$penetrating into the matrix, so the time of reaching chloride critical value in concrete had been significantly delayed; but also had greater internal electrical resistance to inhibit internal $\mathrm{Cl}^{-}$ depolarization and catalyst to the corrosion of steel bar, so the process of the rust generation and cracks inducing by expansive stress of rusted had been postponed. These might be the reasons why the cylinders of C2 hadn't cracked yet when corrosion potential reached $-558 \mathrm{mv}$.

\section{Conclusion}

Use of polypropylene fiber and silica fume modified concrete as a repair material was studied. These results could be summarized as follows:

(1) The addition of fiber without silica fume had little effect on improvement of strength and impermeability.
(2) The incorporation of both polypropylene fiber and silica fume increased compressive strength obviously, and caused a significant reduction in chloride permeability and its corrosion potential of steel bar was higher than others in corresponding period, showing better steel bar protection performance. Therefore, the significant improvement on concrete properties may result from both the anti-cracking effect of polypropylene fiber and densification reinforcement action to the interfacial transition zone of fiber-matrix and aggregate - cement paste by silica fume.

(3) Because of high chloride permeability and excellent steel bar protection performance, use of polypropylene fiber and silica fume modified concrete could provided a kind of durable materials as a repair material.

This research was supported by National Key R\&D Program of China under Grant No. 2017YFB0310005, China Railway Corporation Science and Technology Research and Development Program under Grant No. 2017G002-D and 2017G002-C, China Academy of Railway Science Foundation under Grant No. 2016YJ024 and 2015YJ032, and Shanghai Railway Bureau Foundation under Grant No.2016-17.

\section{References}

1. L. Schueremans, D. Gemert, S. Giessler. Construction and Building Materials. Chloride penetration in RC-structures in marine environment - Long term assessment of a preventive hydrophobic treatment. 21, 1238-1249 (2007)

2. L. Bertolini, B. Elsener, P. Pedeferri, R. Polder. Wiley $\mathrm{VCH}$. Corrosion of Steel in ConcretePrevention, Diagnosis, Repair. (2004)

3. Y. Song, L. Song, G. Zhao. Ocean.Engineering. Factors affecting corrosion and approaches for improving durability of ocean reinforced concrete structures. 31, 779-789 (2004)

4. B. Oh, S. Cha, B. Jang, et al. Nucl. Eng. Des. Development of High-performance Concrete Having High Resistance to Chloride Penetration. 212(1-3), 221-231 (2002)

5. M. Sahmaran, V. Li. Mater. Struct. Influence of Microcracking on Water Absorption and Sorptivity of ECC. 42(5), 593-603 (2009) 